\title{
Oxygen reduction on silver catalysts electrodeposited on various nanocarbon supports
}

\author{
Jonas Mart Linge ${ }^{1} \cdot$ Heiki Erikson $^{1} \cdot$ Maido Merisalu $^{2} \cdot$ Väino Sammelselg $^{2} \cdot$ Kaido Tammeveski $^{1}$ (1)
}

Received: 14 December 2020 / Accepted: 27 January 2021 / Published online: 3 February 2021

(c) The Author(s) 2021 OPEN

\begin{abstract}
In this work, Ag particles were electrodeposited onto nitrogen-doped graphene oxide, graphene, multi-walled carbon nanotube (MWCNT), and Vulcan carbon XC-72R supports by varying the upper potential limit. The surface morphology of the resulting Ag-based catalysts was examined by scanning electron microscopy. The electrochemical oxygen reduction reaction (ORR) was tested in alkaline media employing the rotating disk electrode method. The variation of the upper potential limit influenced the size of silver nanoparticles and their number density on the substrate surface. All the Ag-based electrocatalysts studied in this work showed remarkable ORR activity in terms of half-wave potentials. The ORR results combined with hydrogen peroxide reduction results prove that all Ag catalysts tested are suitable for both reactions. Ag/NGO2 catalyst possesses the highest mass activity for ORR, which indicates a relationship between the $\mathrm{Ag}$ loading and electrocatalytic activity. The electroreduction of oxygen on all the electrodeposited silver catalysts follows a four-electron pathway in alkaline environment. These materials are promising alternatives for $\mathrm{Pt} / \mathrm{C}$ catalyst to be used as alkaline membrane fuel cell cathodes.
\end{abstract}

Keywords Oxygen reduction · Electrocatalysis · Ag catalyst · Peroxide reduction · Kinetics

\section{Introduction}

As energy consumption grows, more sustainable green energy is needed. Renewable energy sources are increasingly employed and low-temperature fuel cells have been taken into serious consideration [1]. For example, anion exchange membrane fuel cells (AEMFCs) use hydrogen gas as a fuel and produce electricity, water vapor, and no $\mathrm{CO}_{2}$. The main obstacle in using the AEMFC technology is its high cost due to Pt catalyst materials, which are currently employed for oxygen reduction reaction (ORR) on the cathode side of the fuel cell [2-6]. Thus novel, cheaper, more stable, and highly active catalysts for replacement of $\mathrm{Pt} / \mathrm{C}$ have been developed during the past decade.
A good substitute to platinum is silver, which has shown in alkaline media comparable ORR performance $[4,7-11]$. The ORR occurs via 4-electron pathway on both electrode materials. Although compared to Pt, silver shows slightly lower activity, it still is an attractive material because of its significantly lower cost [12]. The ORR on silver-based catalyst materials proceeds either through a $2 \mathrm{e}^{-}+2 \mathrm{e}^{-}$reduction, where hydrogen peroxide intermediate forms or via direct four-electron pathway or by both pathways simultaneously [7]. In fuel cells a complete four-electron reduction of $\mathrm{O}_{2}$ is preferred because the formation of peroxide decreases the fuel cell efficiency and can degrade the cathode catalyst material.

Supplementary Information The online version of this article contains supplementary material available at (https://doi.org/10.1007/ s42452-021-04289-x)

Kaido Tammeveski, kaido.tammeveski@ut.ee | ${ }^{1}$ Institute of Chemistry, University of Tartu, Ravila 14a, 50411 Tartu, Estonia. ${ }^{2}$ Institute of Physics, University of Tartu, W. Ostwald Str. 1, 50411 Tartu, Estonia. 
The ORR studies on low-index single-crystal Ag electrodes have shown that this is a structure-sensitive reaction $[11,13]$. When examining the ORR kinetics on single-crystal silver surfaces in alkaline solution Blizanac et al. determined that the ORR activation energy depends on the structure and decrease in the order of $A g(100)>A g(111)>A g(110)$ [13]. They also stated that serial $4 \mathrm{e}^{-}$pathway was the most likely pathway via which the ORR on $\mathrm{Ag}(\mathrm{hkl})$ surfaces would proceed. Structuresensitivity has been also studied on differently shaped Ag nanocatalysts, for example, nanowires, nanocubes, nanoplatelets, nanodecahedra, and nanosheets [14-17]. Lee et al. showed that due to the decreased amount of $\mathrm{Ag}(111)$ planes on Ag nanocubes the specific activity (SA) for $\mathrm{O}_{2}$ reduction increased [14]. It has been also demonstrated that on silver nanocubes with (100) facets $\mathrm{OH}$ species adsorb stronger than on silver nanodecahedra with (111) facets and therefore on Ag decahedra the ORR proceeds likely via direct 4-electron pathway and on $\mathrm{Ag}$ nanocubes via series pathway [15].

Silver nanoparticle (AgNP) size effect plays an important role in Ag electrocatalyst activity towards the ORR and therefore it has received a lot of attention [17-23]. The topic has proved itself to be quite intriguing since size effects have been observed even for larger particles. In a study by Lee et al., it was demonstrated that on silver nanoparticles sized $136.1 \mathrm{~nm}$ the electron transfer number (n) was 3.16, while on $98.7 \mathrm{~nm}$ AgNPs the $n$ value was 3.27 [17]. In another study, it was concluded that on smaller AgNPs $(4.1 \mathrm{~nm})$ the ORR proceeds via both $2 \mathrm{e}^{-}+2 \mathrm{e}^{-}$and four-electron pathways at the same time and on larger ones (174 nm) via 4-electron pathway [18]. In a study conducted by Alia et al., it was reported that decreasing the silver nanowire diameter increases the specific activity for oxygen reduction [19]. Ag nanoparticles showed the opposite results, where the SA value grew with increasing the particle size, and with the increase of the diameters of both silver nanowires and nanoparticles, mass activities (MA) decreased in both cases. Lu et al. studied the ORR on $0.7 \mathrm{~nm}$ Ag nanoclusters and $3.3 \mathrm{~nm}$ silver nanoparticles, and the results showed that SA was 5 times higher on the nanoclusters as compared to nanoparticles [20]. In a study conducted by Ohyama et al., it was concluded that for larger particles than $10 \mathrm{~nm}$ the size effect had an insignificant impact on SA, however the size effect with particles smaller than $3 \mathrm{~nm}$ noticeably affected the SA values because of the quantum size effects and a large amount of coordinatively unsaturated silver atoms [21].

For better efficiency of the catalyst materials, the studies show that silver loading for a complete $4 \mathrm{e}^{-}$ORR process should be higher than $10 \mathrm{wt} \%$ [24-27]. Guo et al. suggested that the reason for the lower than 4 electrons transferred per $\mathrm{O}_{2}$ molecule during the ORR process on
$10 \mathrm{wt} \% \mathrm{Ag} / \mathrm{C}$ is that the reaction proceeds partially on a carbon support due to low amount of silver [27]. The $n$ value is affected by the metal loading as well as by distinct reaction mechanism and the mean crystallite size. The Ag loading of $40 \mathrm{wt} \%$ compared to 10 and $20 \mathrm{wt} \% \mathrm{Ag}$ on multi-wall carbon nanotubes (MWCNT) gave the highest ORR current densities [28]. Larger loading also provides better stability to the electrocatalyst. In a study where the Ag loading was increased from 20 to $60 \mathrm{wt} \%$, the decrease in the $n$ value from 4 to 3.7 was reported [29]. Taking previous work into account, it is clear that in order to prepare electrocatalytically active $\mathrm{Ag} / \mathrm{C}$ catalysts for ORR in alkaline media the loading of Ag should be at least $20 \mathrm{wt} \%$ [30].

Catalyst morphology is strongly affected by substrate materials and as a result many carbon and also non-carbon supports have been tested. Several high-surface-area carbon-based support materials have been used in the preparation of Ag-based catalysts [31]. Carbon nanotubes are one of the most frequently used support materials [32, 33]. AgNPs have been deposited onto MWCNTs using sputterdeposition [34]. In addition to MWCNTs, both graphene [35] and nitrogen-doped graphene (NGO) have received a lot of attention as substrates for silver catalysts [36-38]. Other $\mathrm{N}$-doped carbon supports have also been employed [39] and Vulcan carbon XC-72R has been used as a reference carbon support [30]. Mesoporosity of the support material plays a role in the enhanced electrocatalytic activity of Ag catalysts for ORR [40].

In previous studies, we have electrochemically deposited silver onto a bare glassy carbon electrode both in aqueous and non-aqueous solutions [41, 42]. In this work, we prepared Ag catalysts via electrodeposition in aqueous media using a simple potential cycling procedure, where the upper potential limit was varied to better control the deposition of Ag particles in both size and uniform distribution on carbon supports. In order to study the effect of support materials on the surface morphology of the silver catalyst, Ag particles were deposited onto four nanocarbon supports (NGO, graphene, MWCNT, and Vulcan XC$72 R$ ). The electroreduction of oxygen in alkaline media on these Ag-based catalysts was tested using a rotating disk electrode.

\section{Materials and methods}

\subsection{Synthesis of GO and NGO}

Graphene oxide (GO) was prepared using a modified Hummers method [43] and the GO material was doped with nitrogen to synthesize N-doped GO (NGO), which was used as a substrate $[37,43]$. Briefly, a known amount of graphite was added into a glass flask, to which concentrated sulfuric 
acid $\left(\mathrm{H}_{2} \mathrm{SO}_{4}\right)$ was added and the mixture was sonicated for $1 \mathrm{~h}$. Then the temperature of the mixture was raised to $35^{\circ} \mathrm{C}$ and held for $18 \mathrm{~h}$. In the following step, the mixture was cooled down in an ice bath and deionized water was added to it. In a consecutive step, hydrogen peroxide was added and after that, the suspension was washed with hydrochloric acid. The resulting mixture was washed with copious amount of Milli-Q water (Millipore, Inc.) and dried at $75^{\circ} \mathrm{C}$. After that a known amount of $\mathrm{GO}$ powder was weighed into a beaker to which Milli-Q water and ethanol were added and the mixture was sonicated. While sonicated polyvinylpyrrolidone (PVP) and dicyandiamide (DCDA, Aldrich) were added, as described previously [43]. The resulting mixture was then sonicated for $2 \mathrm{~h}$ and dried at $75^{\circ} \mathrm{C}$. Dry powder was collected and pyrolyzed at $800^{\circ} \mathrm{C}$ for $2 \mathrm{~h}$ under $\mathrm{N}_{2}$ flow. After that the furnace was cooled down and the resulting $\mathrm{N}$-doped graphene oxide material was gathered into a vial.

\subsection{Modification of the electrodes}

Before the electrodeposition, $20 \mu$ l of suspensions ( $1 \mathrm{mg}$ of carbon material in $1 \mathrm{ml}$ ethanol) of NGO, graphene (Gr, Strem Chemicals), Vulcan carbon XC-72R (C, Cabot Corp.), and multi-walled carbon nanotubes (MWCNT, diameter $30 \pm 15 \mathrm{~nm}$, length 5-20 $\mu \mathrm{m}$, purity $>95 \%$, NanoLab Inc., USA) were drop-casted onto glassy carbon (GC) electrodes. MWCNTs were acid-treated before use according to a procedure reported previously [44]. Electrodeposition of $\mathrm{Ag}$ was carried out in aqueous $0.1 \mathrm{M} \mathrm{KNO}_{3}$ solution containing $0.01 \mathrm{mM} \mathrm{AgNO}_{3}$ by cycling between the deposition potential of $-0.6 \mathrm{~V}$ and different upper potential ( 0.3 and $0.4 \mathrm{~V}$ ) for 100 cycles with scan rate of $100 \mathrm{mV} \mathrm{s}^{-1}$. The resulting materials were designated according to the upper potential value. For example, for NGO-supported Ag catalysts when it was $0.3 \mathrm{~V}$ the catalyst was named $\mathrm{Ag} / \mathrm{NGO} 1$ and when the upper potential was $0.4 \mathrm{~V}$ then $\mathrm{Ag} / \mathrm{NGO} 2$. Other Ag-based electrocatalysts were named in the same way.

\subsection{Electrochemical measurements}

The electrochemical measurements were carried out in a standard three-electrode glass cell. A Pt wire was used as a counter electrode, which was separated from the working solution by a glass frit. Saturated calomel electrode (SCE) was used as a reference electrode separated from the working solution by Luggin capillary. Potentials were applied using Autolab PGSTAT30 potentiostat/galvanostat (Metrohm Autolab B.V., The Netherlands), which was controlled by General Purpose Electrochemical System (GPES) software. To carry out the rotating disk electrode (RDE) measurements EDI101 rotator and CTV101 speed control unit (Radiometer) were used and electrode rotation rate
( $\omega)$ was varied from 360 to $4600 \mathrm{rpm}$. A potential scan rate (v) of $10 \mathrm{mV} \mathrm{s}^{-1}$ was used for oxygen reduction and peroxide reduction measurements. All electrochemical experiments were conducted at room temperature $\left(23 \pm 1^{\circ} \mathrm{C}\right)$.

Most of the electrochemical experiments were carried out in $0.1 \mathrm{M} \mathrm{KOH}$ solution, which was made up by dissolving $\mathrm{KOH}$ pellets (puriss p.a., Sigma-Aldrich) in Milli-Q water. To conduct the oxygen reduction measurements the electrolyte solution was saturated with $\mathrm{O}_{2}$ (99.999\%, Linde Gas). The solution was deaerated with $\operatorname{Ar}(99.999 \%$ Linde Gas) for some other experiments, including cyclic voltammetry (CV) and Ag stripping experiments (see Supplementary material). For peroxide reduction experiments, hydrogen peroxide (p.a. 30\%, Lach-Ner) was added to $0.1 \mathrm{M} \mathrm{KOH}$ solution (final concentration $1 \mathrm{mM} \mathrm{HO}_{2}^{-}$).

Glassy carbon disk electrodes with $5 \mathrm{~mm}$ diameter were cut from GC rods (GC-20SS, Tokai Carbon, Japan). The GC disks were mounted into Teflon holders and polished on a 4000 grit emery paper and thereafter with alumina slurries ( 1 and $0.3 \mu \mathrm{m}$, Buehler). After polishing the electrodes were sonicated in both Milli-Q water and 2-propanol in an ultrasonic bath for 3 min. Bulk polycrystalline Ag (99.95\%, Alfa Aesar) electrodes (geometric area $0.2 \mathrm{~cm}^{2}$ ) were used for comparison.

\subsection{Surface characterization of the Ag catalysts}

For the surface morphology characterization, a scanning electron microscope (SEM, Helios ${ }^{\mathrm{TM}}$ Nanolab 600, FEI) with an accelerating voltage of $10 \mathrm{kV}$ and a working distance of $4 \mathrm{~mm}$ was used. Samples for SEM were prepared in the same way as the electrodes for electrochemical experiments and finally removing the modified GC disks from Teflon holders.

\section{Results and discussion}

\subsection{Surface morphology of Ag catalysts on various support materials}

Figures 1 and 2 show SEM micrographs of Ag/NGO, Ag/ MWCNT, Ag/Gr, and Ag/C catalyst materials electrodeposited using two different upper potential limits of 0.3 and $0.4 \mathrm{~V}$, respectively. The largest $\mathrm{Ag}$ particles are mostly agglomerates that are in the submicrometer size range. On all of these SEM images quasi-spherical Ag particles can be observed. The average particle size of the Ag-based catalyst materials varies depending on the deposition procedure used and the size distribution is rather large. The Ag particles are randomly distributed on the carbon support. In our previous work where the silver nanoparticles were electrodeposited onto bare GC disks using different 
Fig. 1 SEM micrographs of a Ag/NGO1, b Ag/Gr1, c Ag/ MWCNT1, and $\mathbf{d} \mathrm{Ag} / \mathrm{C} 1 \mathrm{sam}-$ ples. Scale bar: $400 \mathrm{~nm}$

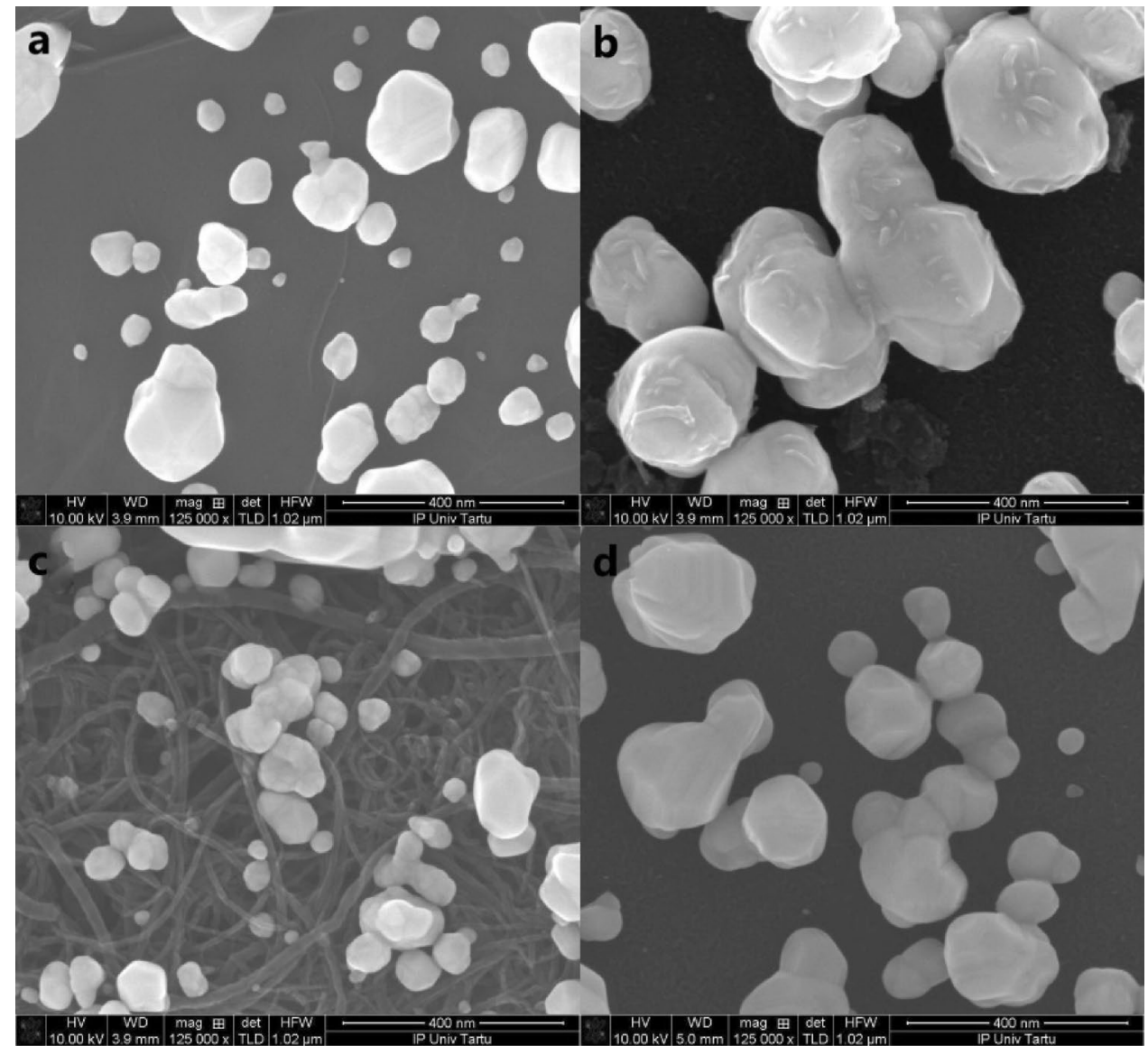

deposition times yielded smaller nanoparticles [41, 42]. During the electrodeposition the upper potential limit was varied and by using a more positive potential smaller silver nanoparticles were deposited and their number density on the substrate surface was also lower. In addition to the deposition environment and controlling the deposition potential and the time (or the number of cycles and the scan rate), the carbon support plays a great role in determining the Ag nanoparticle size and also the distribution of the nanoparticles [37]. From Fig. 1 it can be seen that on the MWCNT surface the silver nanoparticles are the smallest and the distribution of particles is the widest. In this case the upper potential limit of $0.3 \mathrm{~V}$ vs SCE was applied.

\subsection{Oxygen reduction reaction studies}

Before the ORR studies the electrodes were pre-conditioned by cycling in a potential range from -1.2 to $0 \mathrm{~V}$ versus SCE in Ar-saturated 0.1 M KOH solution for 10 potential cycles with scan rate of $100 \mathrm{mV} \mathrm{s}^{-1}$. In this potential range, the silver catalyst surface is not yet oxidized and the rearrangement of silver nanoparticles on all of the carbon supports is avoided. The background currents were measured and subtracted from the corresponding oxygen reduction currents. The ORR measurements were performed in $\mathrm{O}_{2}$-saturated 0.1 M KOH solution using the RDE method. The ORR polarization curves on all silver catalysts were recorded only by anodic scans. It can be seen in Figs. $3 a$ and 4 a that all Ag-based catalysts show only single-wave polarization curves with more positive ORR onset and half-wave potentials $\left(E_{1 / 2}\right)$ than bulk polycrystalline silver electrode (see also Figure S1 in Supplementary material). From all the Ag-based catalyst materials studied Ag/NGO1 possessed the highest ORR electrocatalytic activity (see Table 1). It is evident that a more positive upper potential limit leads to lower $E_{1 / 2}$ values. In a control experiment it was found that by selecting the upper potential limit of $0.5 \mathrm{~V}$ the Ag nanoparticles start to dissolve and therefore less amount of silver is present on the carbon supports. The dissolution of $\mathrm{Ag}$ occurs when the upper potential limit is close to the silver redox potential $\left(\mathrm{Ag}^{+}+\mathrm{e}^{-} \leftrightarrow \mathrm{Ag}^{0}\right)$ of $0.7996 \mathrm{~V}$ vs. standard hydrogen electrode (SHE) [45].

For further analysis of RDE results of the synthesized Ag-based electrocatalysts, the Tafel plots of ORR were constructed (Figs. $3 \mathrm{~b}$ and $4 \mathrm{~b}$ ). It can be seen that Tafel plots of polycrystalline silver, Ag/NGO1, and Ag/MWCNT1 electrodes are almost parallel. The Tafel slope values at low overpotentials are $-92,-60,-95$, and $-93 \mathrm{mV}$ for Ag/Gr1, 
Fig. 2 SEM micrographs of a Ag/NGO2, b Ag/Gr2, c Ag/ MWCNT2, and d Ag/C2 samples. Scale bar: $400 \mathrm{~nm}$
Fig. 3 a Comparison of polarization curves for oxygen reduction on $\mathrm{Ag}$-based catalysts in $\mathrm{O}_{2}$-saturated $0.1 \mathrm{M}$ $\mathrm{KOH}$ solution, $v=10 \mathrm{mV} \mathrm{s}^{-1}$, $\omega=1900 \mathrm{rpm}$. The catalysts are prepared using different nanocarbon supports and upper potential of $0.3 \mathrm{~V}$. $\mathbf{b}$ Mass-transfer corrected Tafel plots for $\mathrm{O}_{2}$ reduction on Agbased catalysts. Data derived from (a)

Fig. 4 a Comparison of polarization curves for oxygen reduction on $\mathrm{Ag}$-based catalysts in $\mathrm{O}_{2}$-saturated $0.1 \mathrm{M}$ $\mathrm{KOH}$ solution, $v=10 \mathrm{mV} \mathrm{s}^{-1}$, $\omega=1900 \mathrm{rpm}$. The catalysts are prepared using different nanocarbon supports and upper potential of $0.4 \mathrm{~V}$. $\mathbf{b}$ Mass-transfer corrected Tafel plots for $\mathrm{O}_{2}$ reduction on Agbased catalysts. Data derived from (a)
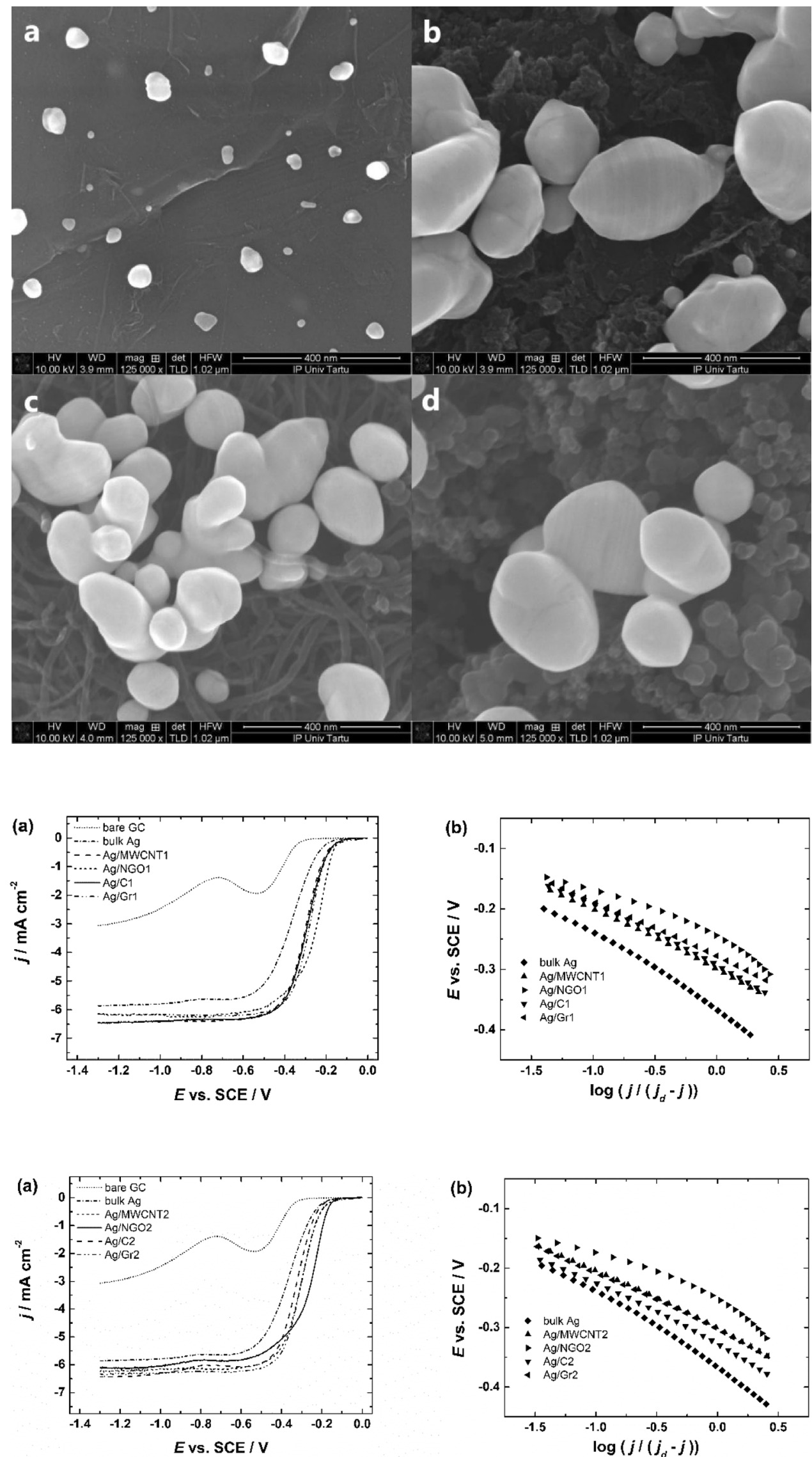

SN Applied Sciences A SPRINGER NATURE journat 
Table 1 Mass of deposited silver $(m)$, half-wave potential $\left(E_{1 / 2}\right)$, and mass activity (MA) of Ag-based electrocatalysts for ORR in $\mathrm{O}_{2}$-saturated $0.1 \mathrm{M} \mathrm{KOH}$ solution. $E_{1 / 2}$ was determined at $1900 \mathrm{rpm}$

\begin{tabular}{lrll}
\hline Catalyst & $m(\mu \mathrm{g})$ & $E_{1 / 2}(\mathrm{~V}$ vs. SCE $)$ & $\begin{array}{l}\text { MA at }-0.2 \mathrm{~V} \mathrm{vs.} \\
\mathrm{SCE}\left(\mathrm{mA} \mu \mathrm{g}^{-1}\right)\end{array}$ \\
\hline $\mathrm{Ag} / \mathrm{Gr} 1$ & 10.92 & -0.299 & 0.049 \\
$\mathrm{Ag} / \mathrm{Gr} 2$ & 7.06 & -0.309 & 0.068 \\
$\mathrm{Ag} / \mathrm{NGO1}$ & 7.46 & -0.261 & 0.048 \\
$\mathrm{Ag} / \mathrm{NGO2}$ & 3.35 & -0.264 & 0.094 \\
$\mathrm{Ag} / \mathrm{MWCNT1}$ & 12.96 & -0.309 & 0.010 \\
$\mathrm{Ag} / \mathrm{MWCNT2}$ & 3.43 & -0.317 & 0.038 \\
$\mathrm{Ag} / \mathrm{C} 1$ & 16.42 & -0.312 & 0.009 \\
$\mathrm{Ag} / \mathrm{C2}$ & 8.53 & -0.329 & 0.010 \\
\hline
\end{tabular}

$\mathrm{Ag} / \mathrm{NGO} 1, \mathrm{Ag} / \mathrm{MWCNT} 1$ and $\mathrm{Ag} / \mathrm{C} 1$ catalysts, respectively. For Ag/Gr2, Ag/NGO2, Ag/MWCNT2, and Ag/C2 materials the slope values are $-96,-59,-93$, and $-92 \mathrm{mV}$, respectively. The Tafel slope values determined in the present work are similar to those obtained for Ag-based catalysts in earlier publications [34, 37, 41, 42, 46-50]. Blizanac et al. reported Tafel plots for ORR on $\mathrm{Ag}(\mathrm{hkl})$ where a change in slope values between -60 and $-120 \mathrm{mV}$ was observed. At lower current densities the Tafel slope was close to $-80 \mathrm{mV}$ and at higher current densities around $-120 \mathrm{mV}$ [13]. Also, in a work where the ORR was investigated on $\mathrm{Ag}$ nanocubes, the Tafel slope values were -60 and $-120 \mathrm{mV}$ at low and high overpotentials, respectively. This change in slope was explained to come from the changes in the adsorption properties of the oxygen intermediates [51]. Changes in the Tafel slope values can also originate from the differences in the Ag loadings on the electrodes, where small Ag loading gives changing slope values, and when critical Ag loading is reached the slope becomes linear [39]. In addition Tafel slopes might be affected by incorrect solution resistance correction [52]. As the Tafel slopes determined in this work are close to the values reported in the literature, it can be concluded that the rate-determining step for the ORR is the slow transfer of the first electron to the adsorbed $\mathrm{O}_{2}$ molecule $[34,37,41,42,46-50]$.
In Fig. 5a a typical set of ORR polarization curves for $\mathrm{Ag} / \mathrm{NGO} 1$ catalyst recorded at different rotation rates is presented. The RDE data was analyzed using the Koutecky-Levich (K-L) equation [53]:

$\frac{1}{j}=\frac{1}{j_{k}}+\frac{1}{j_{d}}=-\frac{1}{n F k C_{O_{2}}^{b}}-\frac{1}{0.62 n F D_{O_{2}}^{2 / 3} v^{-1 / 6} C_{O_{2}}^{b} \omega^{1 / 2}}$

where $j$ is the ORR current density measured at a specific potential, $j_{\mathrm{k}}$ and $j_{\mathrm{d}}$ are kinetic and diffusion-limited current densities, respectively, $n$ is the electron transfer number during the ORR, $F$ is the Faraday constant $\left(96,485 \mathrm{C} \mathrm{mol}^{-1}\right), k$ is the heterogeneous rate constant for $\mathrm{O}_{2}$ reduction at a specific potential $\left(\mathrm{cm} \mathrm{s}^{-1}\right), \mathrm{C}_{\mathrm{O}_{2}}^{b}$ is the concentration of $\mathrm{O}_{2}\left(1.2 \times 10^{-6} \mathrm{~mol} \mathrm{~cm}^{-3}\right)$ [54], $\mathrm{Do}_{2}$ is the diffusion coefficient of $\mathrm{O}_{2}\left(1.9 \times 10^{-5} \mathrm{~cm}^{2} \mathrm{~s}^{-1}\right)$ [54], $v$ is the kinematic viscosity of the solution $\left(0.01 \mathrm{~cm}^{2} \mathrm{~s}^{-1}\right)$ [55], and $\omega$ is the electrode rotation rate $\left(\mathrm{rad} \mathrm{s}^{-1}\right)$.

The electron transfer number $n$ was determined from the K-L plots of Ag/NGO1 (Fig. 5b). The value of $n$ was approximately four for all Ag-based catalysts in this study. From this result, it can be concluded that the ORR proceeds via a 4-electron transfer pathway, thus hydrogen peroxide formation is either almost completely avoided, or the formed hydrogen peroxide is immediately further electrochemically reduced. However, the $K-L$ analysis does not allow differentiating between the direct 4-electron and $2 \mathrm{e}^{-}+2 \mathrm{e}^{-}$pathways, because it yields an overall $n$ value. Guo et al. and Fazil et al. have reported the $n$ value close to four for $40 \mathrm{wt} \% \mathrm{Ag} / \mathrm{CNT}$ catalyst for oxygen reduction in an alkaline environment $[27,28]$. For Ag nanowires [19], through plasma jet treatment prepared silver nanoparticles [46] and Ag nanocubes [14] the $n$ values close to 4 have been reported as well. Silver catalysts deposited onto carbon paper have shown similar $n$ values [56]. In other works where AgNPs were electrodeposited onto bare GC substrate, and the deposition time was varied, the values of $n$ grew with deposition time because of the higher mass of silver on the electrode surface [41,42]. Ag catalysts prepared through heteropolytungstate-assisted fabrication and
Fig. 5 ORR polarization curves for an Ag/NGO1 catalyst at various electrode rotation rates (a) and the corresponding $\mathrm{K}-\mathrm{L}$ plots (b) derived from $\mathbf{a}$; inset shows the dependence of $n$ on potential. Test solution: $\mathrm{O}_{2}$-saturated $0.1 \mathrm{M} \mathrm{KOH}$, $v=10 \mathrm{mV} \mathrm{s}^{-1}$
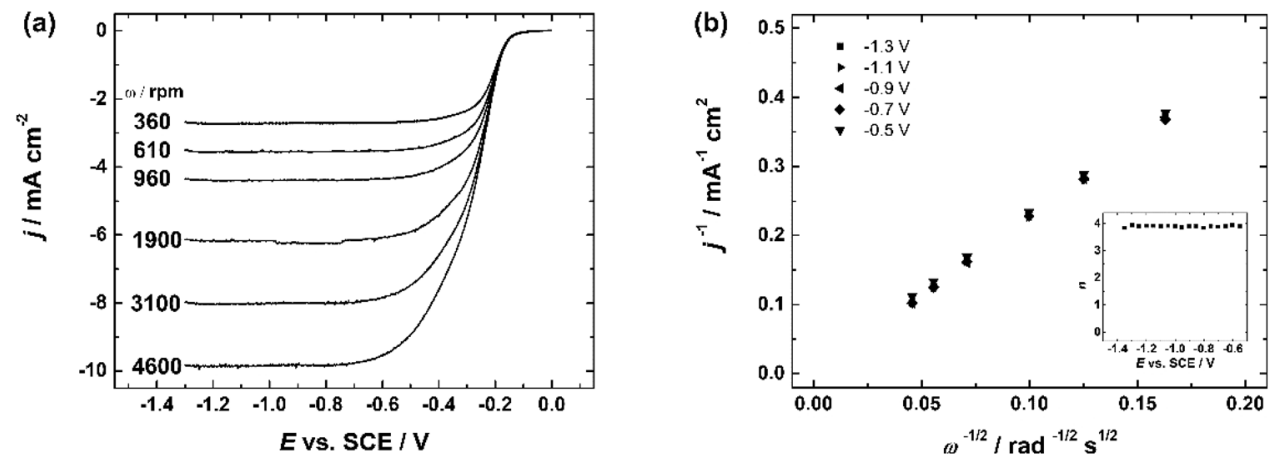
deposition of Ag NPs on reduced graphene oxide ( $\mathrm{rGO}$ ) substrates gave $n$ values close to four as well [50].

To compare the intrinsic electrocatalytic activity of Ag-based catalysts, mass activities (MA) for ORR were calculated using the following equation:

$\mathrm{MA}=I_{\mathrm{k}} / m$

where $I_{\mathrm{k}}$ is the kinetic current determined at $-0.2 \mathrm{~V}$ vs SCE and $m$ is the mass of $\mathrm{Ag}$ on the electrode surface calculated from the Ag dissolution experiments. From Table 1 it can be seen that the highest MA values were obtained for $\mathrm{Ag} / \mathrm{NGO}$ catalysts. $\mathrm{Ag} / \mathrm{C} 1$ possessed the lowest MA value $\left(0.009 \mathrm{~mA} \mathrm{\mu g}^{-1}\right)$, which was closely followed by $\mathrm{Ag} / \mathrm{C} 2$ and $\mathrm{Ag} / \mathrm{MWCNT} 1$ catalyst materials (for both $M A=0.010 \mathrm{~mA} \mathrm{\mu g}^{-1}$ ). This is apparently related to large $\mathrm{Ag}$ particle sizes of these electrocatalysts, and in Figs. 1 and 2 the Ag/NGO catalysts had overall the smallest particles with most uniform distribution. The higher mass activity of $\mathrm{Ag} / \mathrm{NGO}$ catalysts may also be related to synergistic effect between NGO and Ag-particles, and some nitrogen groups make it easier for oxygen molecules to adsorb thus making the reduction of oxygen more efficient [57]. Similar MA values have been reported previously $[21,30]$. In both cases the mass of $\mathrm{Ag}$ on the electrode surface was calculated from the Ag dissolution experiments (see Supplementary material).
Durability of Ag-based catalysts is of utmost importance for their application as cathodes in AEMFCs. Figure 6 shows a comparison of the ORR polarization curves recorded during the stability test. From Fig. 3 it can be seen that $\mathrm{Ag} / \mathrm{NGO} 1$ has the most positive half-wave and onset potential for ORR, thus the stability test was conducted with the Ag/NGO1 catalyst. For comparison a stability test was also conducted with $\mathrm{Ag} / \mathrm{C} 1$ catalyst. For stability experiments, a 1000 potential cycles between -1.3 and $0 \mathrm{~V}$ vs. SCE at a scan rate of $10 \mathrm{mV} \mathrm{s}^{-1}$ were carried out in $\mathrm{O}_{2}$-saturated $0.1 \mathrm{M} \mathrm{KOH}$ solution. The $E_{1 / 2}$ value for $\mathrm{Ag} /$ NGO1 shifted negative only by $20 \mathrm{mV}$ and for $\mathrm{Ag} / \mathrm{C} 1$ only $22 \mathrm{mV}$ and the diffusion-limited current density for both catalysts stayed almost unchanged, which allows us to conclude high stability of these Ag-based catalysts.

\subsection{Hydrogen peroxide reduction studies}

As Ag-based electrocatalysts can also be used as hydrogen peroxide detectors [58], the hydrogen peroxide reduction measurements were carried out as well. In Fig. 7 a typical set of RDE polarization curves for peroxide reduction is presented. The RDE polarization data were further analyzed using the K-L equation, where the diffusion coefficient for $\mathrm{HO}_{2}^{-}$anions is $1.36 \times 10^{-5} \mathrm{~cm}^{2} \mathrm{~s}^{-1}$ [59]. The resulting $n$ value is two for all measured $\mathrm{Ag} / \mathrm{NGO}, \mathrm{Ag} / \mathrm{C}$, $\mathrm{Ag} / \mathrm{Gr}$, and Ag/MWCNT catalysts. This shows that the electroreduction of hydrogen peroxide is efficient on all the
Fig. 6 RDE polarization curves for oxygen reduction on a Ag/ $\mathrm{NGO} 1$ and $\mathbf{b} \mathrm{Ag} / \mathrm{C} 1$ catalysts in $\mathrm{O}_{2}$-saturated $0.1 \mathrm{M} \mathrm{KOH}$ during stability tests. $\omega=1900 \mathrm{rpm}$, $v=10 \mathrm{mV} \mathrm{s}^{-1}$. Number of potential cycles is shown in the legend
Fig. 7 RDE polarization curves for hydrogen peroxide reduction on an Ag/NGO1 catalyst at various electrode rotation rates (a) and the corresponding K-L plots (b) derived from a; inset shows the dependence of $n$ on potential. Test solution: $\mathrm{Ar}$ saturated $0.1 \mathrm{M} \mathrm{KOH}$ containing $1 \mathrm{mM} \mathrm{HO}_{2}{ }^{-}, v=10 \mathrm{mV} \mathrm{s}^{-1}$
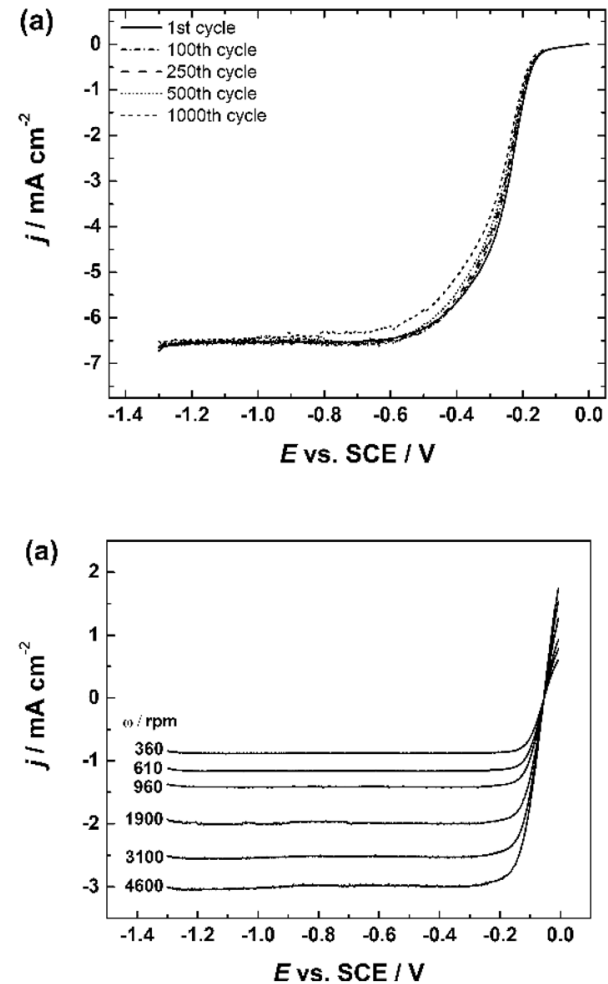
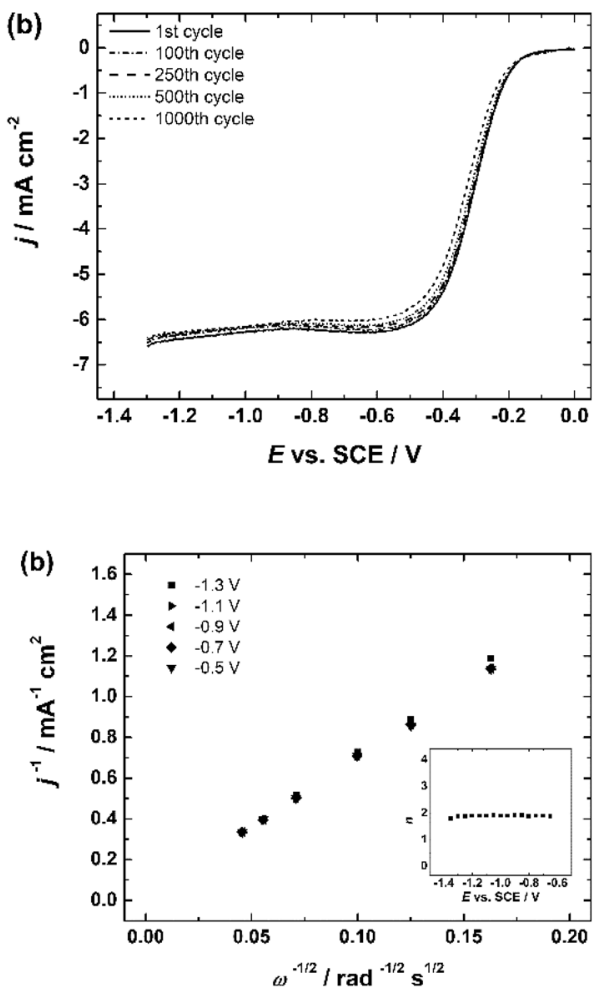

SN Applied Sciences
A SPRINGER NATURE journa 
Ag catalysts studied. It can be thus reasoned that the Agcatalyst materials prepared in this work catalyze the ORR through a 4-electron pathway, however it does not allow one to conclude that the ORR proceeds only via direct $4 \mathrm{e}^{-}$pathway. The assumption that the electroreduction of oxygen on the studied Ag-based catalysts proceeds simultaneously via both 4-electron and $2+2$ electron pathways is more realistic. A similar conclusion has also been made in a work where silver nanoparticles were electrodeposited onto a bare GC substrate [42].

\section{Conclusion}

The Ag-based electrocatalysts were prepared by electrodeposition of silver onto four different carbon substrates by cycling between the deposition potential of $-0.6 \mathrm{~V}$ versus SCE and two different upper potential limits ( 0.3 and $0.4 \mathrm{~V}$ ). The study of the oxygen reduction activity of these Ag catalysts was carried out in $0.1 \mathrm{M} \mathrm{KOH}$ solution. The amount of deposited silver and the size of Ag particles were the biggest when the upper potential was lower $(0.3 \mathrm{~V})$. The RDE results indicate the influence of the upper potential limit on the ORR activity in terms of the onset and half-wave potentials. The $\mathrm{O}_{2}$ reduction results as well as hydrogen peroxide reduction results show that all Agbased catalysts studied in this work are efficient electrocatalysts for both reactions in alkaline media. It was found that $\mathrm{Ag} / \mathrm{NGO} 2$ possessed the biggest mass activity, thus being the most ORR-active catalyst. This indicates about the effect of catalyst loading and carbon substrate on the electrocatalytic activity for ORR. The ORR proceeds via 4-electron pathway on all Ag-based catalysts and Tafel analysis reveals that the rate-determining step is the slow transfer of the first electron to the $\mathrm{O}_{2}$ molecule.

Acknowledgements This work was supported by the Estonian Research Council grant PRG723. This research was also supported by the EU through European Regional Development Fund (TK141, "Advanced materials and high-technology devices for energy recuperation systems"). The Ministry of Education and Research of Estonia is gratefully acknowledged for the support in running the DualBeamTM equipment Helios NanoLabTM through the project IUT2-54.

\section{Compliance with ethical standards}

Conflict of interest The authors declare that they have no conflicts of interest.

Open Access This article is licensed under a Creative Commons Attribution 4.0 International License, which permits use, sharing, adaptation, distribution and reproduction in any medium or format, as long as you give appropriate credit to the original author(s) and the source, provide a link to the Creative Commons licence, and indicate if changes were made. The images or other third party material in this article are included in the article's Creative Commons licence, unless indicated otherwise in a credit line to the material. If material is not included in the article's Creative Commons licence and your intended use is not permitted by statutory regulation or exceeds the permitted use, you will need to obtain permission directly from the copyright holder. To view a copy of this licence, visit http://creativecommons .org/licenses/by/4.0/.

\section{References}

1. Sarapuu A, Kibena-Põldsepp E, Borghei M, Tammeveski K (2018) Electrocatalysis of oxygen reduction on heteroatomdoped nanocarbons and transition metal-nitrogen-carbon catalysts for alkaline membrane fuel cells. J Mater Chem A 6:776-804. https://doi.org/10.1039/c7ta08690c

2. Katsounaros I, Cherevko S, Zeradjanin AR, Mayrhofer KJJ (2014) Oxygen electrochemistry as a cornerstone for sustainable energy conversion. Angew Chem Int Ed 53:102-121. https://doi.org/10.1002/anie.201306588

3. Ge XM, Sumboja A, Wuu D, An T, Li B, Goh FWT, Hor TSA, Zong Y, Liu ZL (2015) Oxygen reduction in alkaline media: from mechanisms to recent advances of catalysts. ACS Catal 5:4643-4667. https://doi.org/10.1021/acscatal.5b00524

4. Spendelow JS, Wieckowski A (2007) Electrocatalysis of oxygen reduction and small alcohol oxidation in alkaline media. Phys Chem Chem Phys 9:2654-2675. https://doi.org/10.1039/ b703315j

5. Shao MH, Chang QW, Dodelet JP, Chenitz R (2016) Recent advances in electrocatalysts for oxygen reduction reaction. Chem Rev 116:3594-3657. https://doi.org/10.1021/acs.chemr ev. 5 b00462

6. Hussain S, Erikson H, Kongi N, Sarapuu A, Solla-Gullón J, Maia G, Kannan AM, Alonso-Vante N, Tammeveski K (2020) Oxygen reduction reaction on nanostructured $\mathrm{Pt}$-based electrocatalysts: a review. Int J Hydrogen Energy 45:31775-31797. https ://doi.org/10.1016/j.ijhydene.2020.08.215

7. Erikson H, Sarapuu A, Tammeveski K (2019) Oxygen reduction reaction on silver catalysts in alkaline media: a minireview. Chem Electro Chem 6:73-86. https://doi.org/10.1002/ celc. 201800913

8. He QG, Cairns EJ (2015) Review-recent progress in electrocatalysts for oxygen reduction suitable for alkaline anion exchange membrane fuel cells. J Electrochem Soc 162:F1504F1539. https://doi.org/10.1149/2.0551514jes

9. Guo Y, Yang M, Xie R-C, Compton RG (2021) The oxygen reduction reaction at silver electrodes in high chloride media and the implications for silver nanoparticle toxicity. Chem Sci 12:397-406. https://doi.org/10.1039/d0sc04295a

10. Chatenet M, Genies-Bultel L, Aurousseau M, Durand R, Andolfatto $F(2002)$ Oxygen reduction on silver catalysts in solutions containing various concentrations of sodium hydroxide: comparison with platinum. J Appl Electrochem 32:1131-1140. https://doi.org/10.1023/a:1021231503922

11. Blizanac BB, Ross PN, Markovic NM (2007) Oxygen electroreduction on $\mathrm{Ag}$ (111): the $\mathrm{pH}$ effect. Electrochim Acta 52:22642271. https://doi.org/10.1016/j.electacta.2006.06.047

12. Sleightholme AES, Varcoe JR, Kucernak AR (2008) Oxygen reduction at the silver/hydroxide-exchange membrane interface. Electrochem Commun 10:151-155. https://doi. org/10.1016/j.elecom.2007.11.008

13. Blizanac BB, Ross PN, Markovic NM (2006) Oxygen reduction on silver low-index single-crystal surfaces in alkaline solution: rotating ring Disk(Ag(hkl)) studies. J Phys Chem B 110:47354741. https://doi.org/10.1021/jp056050d

14. Lee CL, Tsai YL, Huang CH, Huang KL (2013) Performance of silver nanocubes based on electrochemical surface area for 
catalyzing oxygen reduction reaction. Electrochem Commun 29:37-40. https://doi.org/10.1016/j.elecom.2013.01.009

15. Wang QY, Cui XQ, Guan WM, Zhang L, Fan XF, Shi Z, Zheng WT (2014) Shape-dependent catalytic activity of oxygen reduction reaction (ORR) on silver nanodecahedra and nanocubes. J Power Sources 269:152-157. https://doi.org/10.1016/j.jpows our.2014.06.160

16. Lee $\mathrm{CL}$, Syu CC (2011) Electrochemical growth and oxygen reduction property of $\mathrm{Ag}$ nanosheet arrays on a $\mathrm{Ti} / \mathrm{TiO} 2$ electrode. Int J Hydrogen Energy 36:15068-15074. https://doi. org/10.1016/j.ijhydene.2011.08.075

17. Lee CL, Chiou HP, Syu CM, Wu CC (2010) Silver triangular nanoplates as electrocatalyst for oxygen reduction reaction. Electrochem Commun 12:1609-1613. https://doi.org/10.1016/j.eleco m.2010.09.007

18. Han JJ, Li N, Zhang TY (2009) Ag/C nanoparticles as an cathode catalyst for a zinc-air battery with a flowing alkaline electrolyte. J Power Sources 193:885-889. https://doi.org/10.1016/j.jpows our.2009.02.082

19. Alia SM, Duong K, Liu T, Jensen K, Yan YS (2012) Supportless silver nanowires as oxygen reduction reaction catalysts for hydroxide-exchange membrane fuel cells. ChemSusChem 5:1619-1624. https://doi.org/10.1002/cssc.201100684

20. Lu YZ, Chen W (2012) Size effect of silver nanoclusters on their catalytic activity for oxygen electro-reduction. J Power Sources 197:107-110. https://doi.org/10.1016/j.jpowsour.2011.09.033

21. Ohyama J, Okata Y, Watabe N, Katagiri M, Nakamura A, Arikawa H, Shimizu K-i, Takeguchi T, Ueda W, Satsuma A (2014) Oxygen reduction reaction over silver particles with various morphologies and surface chemical states. J Power Sources 245:998-1004. https://doi.org/10.1016/j.jpowsour.2013.07.034

22. Yang YF, Zhou YH (1995) Particle-size effects for oxygen reduction on dispersed silver plus carbon electrodes in alkaline-solution. J Electroanal Chem 397:271-278. https://doi. org/10.1016/0022-0728(95)04178-7

23. Singh P, Buttry DA (2012) Comparison of oxygen reduction reaction at silver nanoparticles and polycrystalline silver electrodes in alkaline solution. J Phys Chem C 116:10656-10663. https:// doi.org/10.1021/jp301676n

24. Garcia AC, Gasparotto LHS, Gomes JF, Tremiliosi-Filho G (2012) Straightforward synthesis of carbon-supported Ag nanoparticles and their application for the oxygen reduction reaction. Electrocatalysis 3:147-152. https://doi.org/10.1007/s1267 8-012-0096-z

25. Vinodh R, Sangeetha D (2012) Carbon supported silver (Ag/C) electrocatalysts for alkaline membrane fuel cells. J Mater Sci 47:852-859. https://doi.org/10.1007/s10853-011-5863-3

26. Xu XH, Tan C, Liu HJ, Wang F, Li ZL, Liu JJ, Ji L (2013) Carbon black supported ultra-high loading silver nanoparticle catalyst and its enhanced electrocatalytic activity towards oxygen reduction reaction in alkaline medium. J Electroanal Chem 696:9-14. https ://doi.org/10.1016/j.jelechem.2013.02.018

27. Guo JS, Hsu A, Chu D, Chen RR (2010) Improving oxygen reduction reaction activities on carbon-supported Ag nanoparticles in alkaline solutions. J Phys Chem C 114:4324-4330. https://doi. org/10.1021/jp910790u

28. Fazil A, Chetty R (2014) Synthesis and evaluation of carbon nanotubes supported silver catalyst for alkaline fuel cell. Electroanalysis 26:2380-2387. https://doi.org/10.1002/elan.20140 0246

29. Hernandez-Rodriguez MA, Goya MC, Arevalo MC, Rodriguez JL, Pastor E (2016) Carbon supported Ag and Ag-Co catalysts tolerant to methanol and ethanol for the oxygen reduction reaction in alkaline media. Int J Hydrogen Energy. 41:19789-19798. https ://doi.org/10.1016/j.ijhydene.2016.07.188
30. Linge JM, Erikson $H$, Merisalu M, Matisen L, Käärik M, Leis J, Sammelselg V, Aruväli J, Kaljuvee T, Tammeveski K (2018) Oxygen reduction on silver nanoparticles supported on carbidederived carbons. J Electrochem Soc 165:F1199-F1205. https:// doi.org/10.1149/2.0711814jes

31. Guo ZQ, Zhang HZ, Ma XC, Zhou XM, Liang D, Mao JF, Fang HY, Yu JM, Sun Y, Huang TZ (2020) Synergistic catalytic effect of hollow carbon nanosphere and silver nanoparticles for oxygen reduction reaction. Chemistry Select 5:8099-8105. https://doi. org/10.1002/slct.202001851

32. Kostowskyj MA, Gilliam RJ, Kirk DW, Thorpe SJ (2008) Silver nanowire catalysts for alkaline fuel cells. Int J Hydrogen Energ 33:5773-5778. https://doi.org/10.1016/j.ijhydene.2008.05.040

33. Kostowskyj MA, Kirk DW, Thorpe SJ (2010) Ag and Ag-Mn nanowire catalysts for alkaline fuel cells. Int J Hydrogen Energ 35:5666-5672. https://doi.org/10.1016/j.ijhydene.2010.02.125

34. Tammeveski L, Erikson H, Sarapuu A, Kozlova J, Ritslaid P, Sammelselg V, Tammeveski K (2012) Electrocatalytic oxygen reduction on silver nanoparticle/multi-walled carbon nanotube modified glassy carbon electrodes in alkaline solution. Electrochem Commun 20:15-18. https://doi.org/10.1016/j. elecom.2012.04.003

35. Ren YQ, Zhao H, Li JP, Wang R, Wei ZH (2020) Facile preparation of a Ag/graphene electrocatalyst with high activity for the oxygen reduction reaction. RSC Adv 10:15650-15655. https ://doi.org/10.1039/d0ra02127j

36. Lopes JH, Colson FX, Ye SY, Gostick JT, Barralet JE, Merle G (2017) Graphene modified nanosized Ag electrocomposites. Mater Res Bull 89:42-50. https://doi.org/10.1016/j.materresbu II.2016.12.046

37. Linge JM, Erikson $H$, Sarapuu A, Merisalu M, Rähn M, Matisen L, Sammelselg V, Tammeveski K (2017) Electroreduction of oxygen on nitrogen-doped graphene oxide supported silver nanoparticles. J Electroanal Chem 794:197-203. https://doi. org/10.1016/j.jelechem.2017.04.022

38. Jiang RZ, Moton E, McClure JP, Bowers Z (2014) A highly active and alcohol-tolerant cathode electrocatalyst containing $\mathrm{Ag}$ nanoparticles supported on graphene. Electrochim Acta 127:146-152. https://doi.org/10.1016/j.electacta.2014.01.134

39. Panomsuwan G, Chantaramethakul J, Chokradjaroen C, Ishizaki T (2019) In situ solution plasma synthesis of silver nanoparticles supported on nitrogen-doped carbons with enhanced oxygen reduction activity. Mater Lett 25:135-139. https://doi.org/10.1016/j.matlet.2019.05.052

40. Zhang ZW, Li HN, Hu J, Liu BZ, Zhang QR, Fernandez C, Peng QM (2017) High oxygen reduction reaction activity of C-N/Ag hybrid composites for Zn-air battery. J Alloy Compd 694:419428. https://doi.org/10.1016/j.jallcom.2016.10.031

41. Linge JM, Erikson H, Kozlova J, Sammelselg V, Tammeveski $\mathrm{K}$ (2018) Oxygen reduction reaction on electrochemically deposited silver nanoparticles from non-aqueous solution. J Electroanal Chem 810:129-134. https://doi.org/10.1016/j.jelec hem.2018.01.009

42. Linge JM, Erikson H, Kozlova J, Aruväli J, Sammelselg V, Tammeveski K (2018) Oxygen reduction on electrodeposited silver catalysts in alkaline solution. J Solid State Electrochem 22:81-89. https://doi.org/10.1007/s10008-017-3724-y

43. Vikkisk M, Kruusenberg I, Joost U, Shulga E, Kink I, Tammeveski $\mathrm{K}$ (2014) Electrocatalytic oxygen reduction on nitrogen-doped graphene in alkaline media. Appl Catal B-Environ 147:369376. https://doi.org/10.1016/j.apcatb.2013.09.011

44. Alexeyeva N, Tammeveski K (2007) Electrochemical reduction of oxygen on multiwalled carbon nanotube modified glassy carbon electrodes in acid media. Electrochem Solid State Lett 10:F18-F21. https://doi.org/10.1149/1.2713657 
45. Haynes WM (2012) CRC handbook of chemistry and physics, 93d edn. CRC Press, Boca Raton

46. Treshchalov A, Erikson $H$, Puust L, Tsarenko S, Saar R, Vanetsev A, Tammeveski K, Sildos I (2017) Stabilizer-free silver nanoparticles as efficient catalysts for electrochemical reduction of oxygen. J Colloid Interf Sci 491:358-366. https://doi. org/10.1016/j.jcis.2016.12.053

47. Linge JM, Erikson H, Kasikov A, Rähn M, Sammelselg V, Tammeveski K (2019) Oxygen reduction reaction on thin-film Ag electrodes in alkaline solution. Electrochim Acta 325:134922. https://doi.org/10.1016/j.electacta.2019.134922

48. Zhao W, Huang K, Zhang Q, Wu H, Gu L, Yao K, Shen Y, Shao Y (2019) In-situ synthesis, operation and regeneration of nanoporous silver with high performance toward oxygen reduction reaction. Nano Energy 58:69-77. https://doi.org/10.1016/j. nanoen.2019.01.021

49. Jin S, Chen M, Dong H, He B, Lu H, Su L, Dai W, Zhang Q, Zhang X (2015) Stable silver nanoclusters electrochemically deposited on nitrogen-doped graphene as efficient electrocatalyst for oxygen reduction reaction. J Power Sources 274:1173-1179. https://doi. org/10.1016/j.jpowsour.2014.10.098

50. Zoladek S, Blicharska-Sobolewska M, Krata AA, Rutkowska IA, Wadas A, Miecznikowski K, Negro E, Vezzù K, Di Noto V, Kulesza PJ (2020) Heteropolytungstate-assisted fabrication and deposition of catalytic silver nanoparticles on different reduced graphene oxide supports: electroreduction of oxygen in alkaline electrolyte. J Electroanal Chem 875:114694. https://doi. org/10.1016/j.jelechem.2020.114694

51. Chao YJ, Lyu YP, Wu ZW, Lee CL (2016) Seed-mediated growth of Ag nanocubes and their size-dependent activities toward oxygen reduction reaction. Int J Hydrogen Energy 41:3896-3903. https://doi.org/10.1016/j.ijhydene.2015.12.176

52. Wiberg GKH, Mayrhofer KJJ, Arenz M (2010) Investigation of the oxygen reduction activity on silver - a rotating disc electrode study. Fuel Cells 10:575-581. https://doi.org/10.1002/fuce.20090 0136
53. Bard AJ, Faulkner LR (2001) Electrochemical methods, 2nd edn. John Wiley \& Sons, New York

54. Davis RE, Horvath GL, Tobias CW (1967) The solubility and diffusion coefficient of oxygen in potassium hydroxide solutions. Electrochim Acta 12:287-297. https://doi.org/10.1016/00134 686(67)80007-0

55. Lide DR (2001) CRC handbook of chemistry and physics, 82 nd edn. CRC Press, Boca Raton

56. Salome S, Rego R, Oliveira MC (2013) Development of silvergas diffusion electrodes for the oxygen reduction reaction by electrodeposition. Mater Chem Phys 143:109-115. https://doi. org/10.1016/j.matchemphys.2013.08.026

57. Cao C, Wei LL, Su M, Wang G, Shen JQ (2017) Template-free and one-pot synthesis of N-doped hollow carbon tube @ hierarchically porous carbon supporting homogeneous AgNPs for robust oxygen reduction catalyst. Carbon 112:27-36. https:// doi.org/10.1016/j.carbon.2016.10.083

58. Zhao XL, Deng ZY, Zhao W, Feng B, Wang M, Huang MR, Liu L, Zou GS, Shao Y, Zhu HW (2020) Nanoporous silver using pulsed laser deposition for high-performance oxygen reduction reaction and hydrogen peroxide sensing. Nanoscale 12:1941319419. https://doi.org/10.1039/d0nr05395c

59. Neumann CCM, Laborda E, Tschulik K, Ward KR, Compton RG (2013) Performance of silver nanoparticles in the catalysis of the oxygen reduction reaction in neutral media: efficiency limitation due to hydrogen peroxide escape. Nano Res 6:511-524. https:// doi.org/10.1007/s12274-013-0328-4

Publisher's Note Springer Nature remains neutral with regard to jurisdictional claims in published maps and institutional affiliations. 